\title{
A Review of Minimum Quantity Lubrication Technique with Nanofluids Application in Metal Cutting Operations
}

\author{
Safian Sharif", Ibrahim Ogu Sadiq ${ }^{\#}$, Noordin Mohd Yusof ${ }^{\#}$, Amrifan Saladin Mohruni*

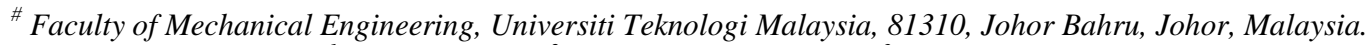 \\ E-mail: 'safian@utm.my, ${ }^{2}$ ogusadiq78@gmail.com, ${ }^{3}$ noordin@fkm.utm.my \\ * Faculty of Engineering, Sriwijaya University, 30662, Palembang, Indonesia.
}

E-mail: mohrunias@unsri.ac.id

\begin{abstract}
Minimum quantity lubrication (MQL) technique did not only serve as a better alternative to flood cooling during machining but enhance better surface finish, minimizes the cost, reduces the impact loads on the environment and health hazards on the operation personnel. However, the coolant or lubrication media used in MQL technique posed certain restrictions especially at very high cutting speeds where the lubricating oil tends to evaporates as it strikes the already heated cutting tool at elevated temperature. Desire to compensate for the shortcomings of the lubricating media in the MQL technique led to the introduction of nanoparticles in the cutting fluids for use in the MQL lubrication process. Nanoparticles have much higher and stronger temperature-dependent thermal conductivity and enhanced heat transfer coefficient at very low particle concentration, which are key parameters for their enhanced performance in many of the machining applications. Optimizing the nanoparticles concentration leads to efficiency in most of their application. Their ball bearing effect lubrication at the cutting zone through formation of film layer which reduces friction between the contact surfaces thereby reducing cutting force, temperature and tool wear. It has been reported in various studies that nanoparticles introduction in cutting fluids led to excellent machining performance in reduction of cutting forces, reduced tool wear, reduced cutting temperature and improved surface finish of the work piece thereby increasing productivity and reduction of hazards to the health of personnel and the environment better than the pure or conventional MQL process. Thus, the application of various nanoparticles and its performances in metal cutting operations with respect to the cutting forces, surface finish, tool wear and temperature at the cutting zone are evaluated and highlighted.
\end{abstract}

Keywords - nanofluids; nanoparticles; MQL lubrication; cutting fluid; friction; thermal conductivity

\section{INTRODUCTION}

Cutting fluids are essential component of machining process as it cools the cutting zone, lubricates the tool chip contact thereby reducing the friction and temperature generated at the cutting zone. Even though cutting fluids have a reasonably low cost, their handling and carrying costs are very high and, owing to their toxic nature, disposal of used fluids is a big problem because of its hazards to operators and the environment [1], [2]. Transition of the metal working industries towards sustainable manufacturing can be seens in the limitation of the use of conventional coolant and coolant strategies [3]. Researches in the machining industry are gear towards achieving green machining environment without compromising efficient machining operation and output. Among the alternative ways of conventional coolant usage reduction, dry machining and those using compressed air and minimum quality lubrication (MQL) technique [4] or using cool air or cryogenic [5] when machining operation is considered as environmentally friendly. MQL technique which has not only provided an alternative to flood cooling or dry machining because of enhanced and efficient machining process, reduction of hazard to operators and the environment also gave better performance with reduced oil consumption, in terms of surface quality of the output product. Several researches indicates that MQL lubrication technique is beneficial to metal cutting process when compared to dry machining, flood cooling, cryogenic cooling or cool air. The MQL technique provides superior lubricate and less wear on the tool during end milling of marten site stainless steel due to the formation of a thin film that protects the tool from excessive wear was reported [6]. MQL in comparison with flood cooling and dry machining drastically minimize (1/300,000 times) the negative effect on the environment and operator's physiology, resulting from ample use of coolant in milling and reduces the cutting force considerably in comparison with dry cutting respectively [7]. However, the 
lubricating oil in the MQL technique tends to evaporates as it strikes the already heated cutting tool at high temperature. Thus, the MQL cooling/lubrication technique becomes less effective in ensuring efficient machining process especially when high speed machining is involved. The need for coolant that will amongst other things withstand excessive heat generated in the cutting zone, reduction of friction and lowering cutting force necessitated the introduction of high thermal conductivity nanoparticles in the base cutting fluids to eliminate or reduce drastically the shortcomings of the conventional coolants in MQL techniques. Nanofluids are new classes of fluids engineered by dispersing nanometerized materials (nanoparticles, nanofibers, nanotubes, nanorods etc) usually in the range of $1 \sim 100 \mathrm{~nm}$ in based fluids which could be deionized water, mineral, esters or vegetable oils [8].

\section{MATERIAL AND METHOD}

The concept of nanofluid was first coined [9] at Argonne National Laboratory but have since then generated much interest due to its great heat transfer enhancement as reported [9], [10], mass transfer [11], and wetting and spreading [12]. It is an established fact that metals in solid form at room temperature possess higher thermal conductivities than those of base fluids [13]. Investigation conducted by several researchers reveals that nanoparticles enhanced the inherent properties of the based fluids and tend to improve the thermal performances of the working fluids.

Approximately 20\% increase of thermal conductivity was attained when $\mathrm{CuO}$ nanoparticles was used in a suspension of ethylene glycol [14]. The thermal conductivity of $0.3 \%$ copper nanoparticles in ethylene glycol based fluid increased by $40 \%$ in comparison to that of the base fluid [15]. The addition of Multi-Walled Carbon Nanotubes (MWCNT) could increase the thermal conductivity of nanofluids up to $150 \%$ [16]. Nanofluids in comparison with base fluids possess higher thermal conductivity, heat transfer coefficient, higher viscosity, flash and fire points [17]. Nanofluids can used to improve heat transfer and energy efficiency in a variety of thermal systems [18]. They found to have great potential in heat transfer enhancement, which made them suitable for practical application in heat transfer and thermal engineering processes [19]. The heat transfer improvement of about $40 \%$ can obtain when compared to the base fluid of $\mathrm{Al} 2 \mathrm{O} 3$ [20]. For copper oxide ( $\mathrm{CuO})$-water nanofluid at $2 \%$ volume concentration, the overall heat transfer coefficient and pumping power are more than that of the base fluid [21]. Nanofluids has been utilized extensively in the convective heat transfer applications. The internal combustion engine performance improved by $10 \%$ with the use of nanoparticle suspended in commercial engine coolant [22]. They have much higher and stronger temperature-dependent thermal conductivity and its value increases with particles concentration [23]. This property of nanofluids as shown in Figures $1 \mathrm{a} \& 1 \mathrm{~b}$, is a key parameter for their excellent performance in many of the heat transfer applications.

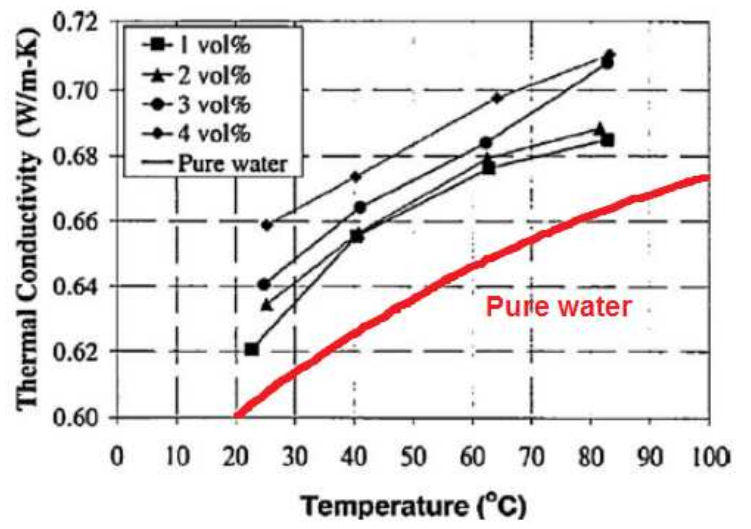

Fig. 1a Temperature-dependent Thermal Conductivity [23]

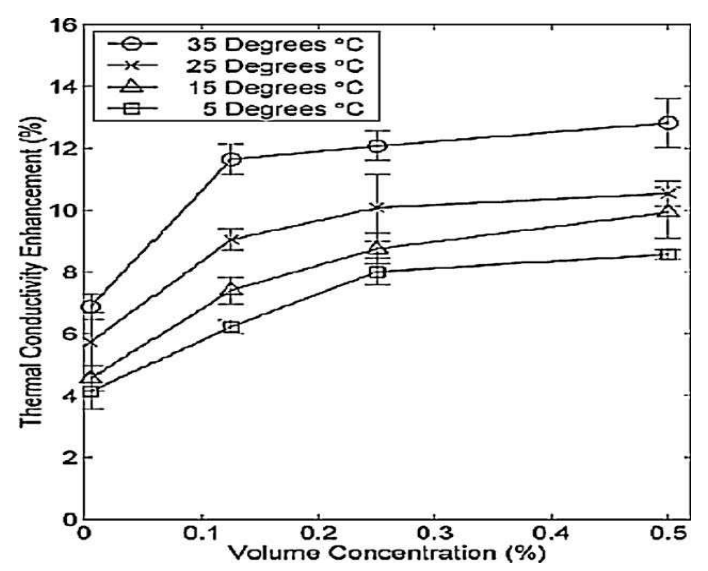

Fig. 1b Thermal conductivity enhancement as function of volume concentration [23]

\section{A. Nanofluid Application with MQL in Machining}

Friction and wear result in the increase of energy consumption and the reduction in the life of mechanical parts. Application of nanofluids as coolant and lubricant results in lower tool temperature, lower tool wear, better surface quality and minimised environmental dangers [24] than most other oils and conventional coolants. Nanofluids are known to enhance the tribological properties of base fluids. The tribological properties of graphite nanoparticles as a vegetable-based oil additive with a pin-on-disk friction and wear tester was investigated [25]. They reported that friction reducing and anti-wear properties of the pure oil were significantly improved by the graphite nanoparticles addition. Further improvement of the MQL technique was achieved with the introduction of nano lubrication into metal cutting processes, which confers rolling action of billions of nanoparticles at the tool chip interface thereby reducing friction and thermal deformation of the work piece in addition to less consumption of lubricating oil as well as reduced pollution activities [26]. Some of the nanoparticles used for nanofluid application in metal cutting processes includes but not limited to the followings: exfoliated nanographene $(\mathrm{xGnP})$, hexagonal boron nitride $(\mathrm{hBN})$, copper oxide $(\mathrm{CuO})$, aluminium oxide $\left(\mathrm{Al}_{2} \mathrm{O}_{3}\right)$, molybdenum disulphide $\left(\mathrm{MoS}_{2}\right)$, carbon nanotubes $(\mathrm{CNT})$, iron oxide $\left(\mathrm{Fe}_{2} \mathrm{O}_{3}\right)$, nanographite, multi wall carbon nanotubes (MWCNTs), nanoboric acid, silicon oxide $\left(\mathrm{SiO}_{2}\right)$, titanium oxide $\left(\mathrm{TiO}_{2}\right)$, silicon carbide $(\mathrm{SiC})$ nanodiamond, etc. 
Improvements through the introduction of nanofluid in MQL technique of lubrication during machining operation in all the traditional machining processes highlighted below.

1) Grinding Operation: Nanofluid applications with MQL technique in grinding operation have been reported by several researchers. The effect of nanofluid MQL on the grinding characteristics during the grinding of titanium alloy with silicon carbide grinding wheel, $\mathrm{SiC}$ (CGC60-K5-VG) using four different lubrication media (water based Castrol oil cutting oil at 1:40 concentration, pure water and waterbased $\mathrm{Al}_{2} \mathrm{O}_{3}$ nanofluids of $1 \%$ and $4 \%$ concentration) were studied [27]. The experiments conducted on a SMARTH1224 surface grinding machine with the following conditions: grinding parameters: wheel speed (10.89, 16.34 and $21.79 \mathrm{~m} / \mathrm{sec})$, table speed (3, 9 and $15 \mathrm{~m} / \mathrm{min})$ and depth of cut $(10,20$ and $30 \mu \mathrm{m})$. The flowrate and air pressure for the MQL grinding are $18 \mathrm{ml} / \mathrm{hr}$ and 1.5 bar respectively. The grinding forces measured online with a KISTLER 9257B piezoelectric dynamometer, coupled to KISTLER 5070A multichannel (six components) amplifier and computer data acquisition software (Dyno Ware). The mean value was taken after each pass. The ground surface roughness on the other hand was measured by Taylor Hobson Talysurf Profilometer. They reported that grinding forces reduced significantly using nano cutting fluid even at lower concentration of nanoparticles as shown in Fig. 2a, while surface finish improved significantly with increase of nanoparticle concentration when compared with conventional coolant and pure water under MQL. In addition, the cutting force both in normal and tangential were reduced effectively nano- $\mathrm{Al}_{2} \mathrm{O}_{3}$ which can be attributed to the enhanced lubrication and cooling characteristics of the nano-cutting fluid.

The effect of carbon nanotubes (CNTs) and molybdenum disulphide $\left(\mathrm{MoS}_{2}\right)$ nanoparticles concentration on the grinding ratio $(\mathrm{G})$ and surface quality of the ground workpiece under MQL grinding of Ni-based alloy was investigated [28]. The experiments conducted using K-P36 numerical control precision surface grinder, nanofluid transfer device (Bluebe MQL supply system) and the measuring cell YDM-III99 3D dynamometer and TIME3220 roughness tester to measure the grinding forces and the surface roughness for all cutting condition respectively. They reported that increase of concentration was enhanced lowers grinding force ratio $(\mathrm{G})$ which improves lubrication and better surface quality as shown in Fig. 2b. All the cases of nanoparticle inclusion in MQL indicated a superior performance over pure MQL grinding with grinding force ratio $(\mathrm{G})$ of $0.274,0.281$ and 0.293 for CNTs-MoS 2 mixed, $\mathrm{MoS}_{2}$ and CNTs nanofluids respectively as compared to 0.347 of pure MQL lubrication. Water based aluminium oxide $\left(\mathrm{Al}_{2} \mathrm{O}_{3}\right)$ and diamond nanofluids was used in the MQL grinding process [29]. They compared the wheel wear and tribological characteristics in wet (pure water), dry, and MQL grinding processes with nanoparticle grinding of cast iron. They reported a reduction in grinding forces, improved surface roughness and lower grinding temperature with MQL nanoparticles lubricant.

The effect of a nanofluid MQL during micro-grinding process of a tool steel material with a CBN 270 grinding tool in a series of experiments under four different lubrication media (nano-diamond of 2 level concentration, nano- $\mathrm{Al}_{2} \mathrm{O}_{3}$ of 2-level concentration, dry air and pure MQL of the paraffin based oil) was studied by [30] in 2012. The experiments carried out in a miniaturized grinding machine tool system with the following grinding conditions: spindle speed- $80000 \mathrm{rpm}$, feed rate $120 \mathrm{~mm} / \mathrm{min}$ and depth of cut- 5 $\mu \mathrm{m}$. The flowrate for MQL mist are $7.5 \mathrm{cc} / \mathrm{hr}$ for the nanofluid and base oil, while the dry air was supplied at 410 $1 / \mathrm{min}$. The force signals obtained by a 2 -axis load cell attached to the DC motor-driven slide. Two levels of three independent variables - nanoparticles size, concentration and size considered in the experiments. The nanoparticles concentration considered are $2 \%$ vol. and $4 \%$ vol. while particle size of $30 \mathrm{~nm}$ and $150 \mathrm{~nm}$ selected for both nanodiamond and nano- $\mathrm{Al}_{2} \mathrm{O}_{3}$. They observed that the inclusion of nanoparticles (nanodiamonds and nano $\mathrm{Al}_{2} \mathrm{O}_{3}$ ) in paraffin oil based MQL produces a significant reduction of grinding forces and improving surface quality in microgrinding process. In addition, they stated that surface roughness better enhanced with smaller particle size nanoparticles as they produce smoother surface in comparison with larger particle size of $150 \mathrm{~nm}$. Nano- $\mathrm{Al}_{2} \mathrm{O}_{3}$ particles are more effective than nanodiamond particles for reducing surface roughness especially in the case of larger particle size, which easily attributed to the smaller hardness of nano- $\mathrm{Al}_{2} \mathrm{O}_{3}$ particles than that of the nanodiamond.

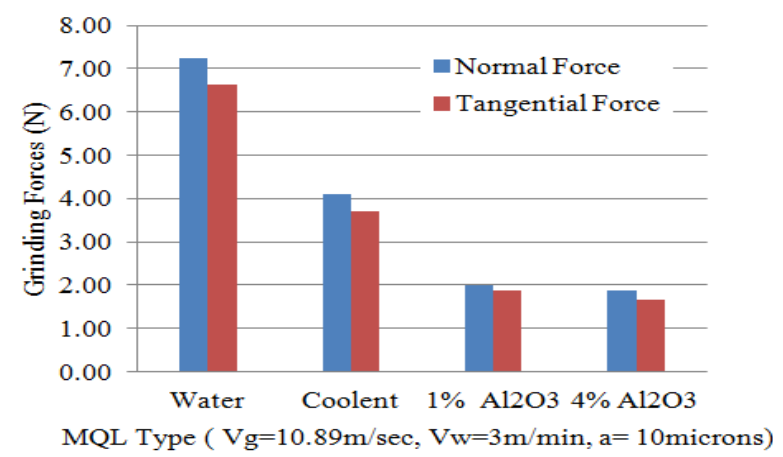

Fig. 2a Grinding forces using MQL under various cooling media [27]

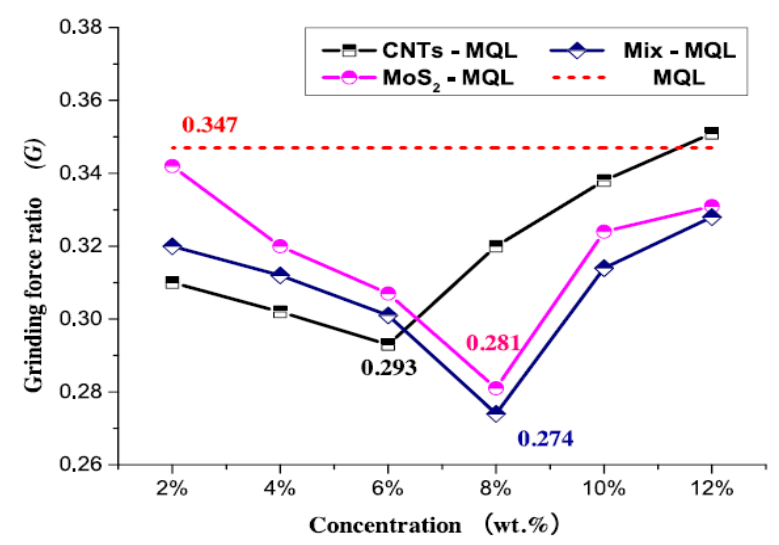

Fig. 2b Grinding force ratios under condition of pure MQL and nanofluids [28]

2) Drilling Operations: Drilling operations in metal cutting industries have enhanced with improved lubrication methodologies. Characterization experiment of microdrilling process using nano-diamond particles suspensions in 
paraffin and vegetable oils with uncoated carbide twist drills (DIXI 1138) for making of holes in Aluminium 6061 workpiece was conducted [31]. The experiments conducted under the following conditions: spindle speed, feed rate and drilling depth of $60,000 \mathrm{rpm}, 50 \mathrm{~mm} / \mathrm{min}$ and $0.4 \mathrm{~mm}$ respectively under fours lubrication environments of compressed air, pure MQL of paraffin and vegetable oils and nanofluids of two level inclusions in the paraffin and vegetable oils. The spherical shaped nano-diamond of $30 \mathrm{~nm}$ particle size dispersed at $1 \%$ and $2 \%$ nano-diamond inclusions in each of the base oils to prepare the nanofluids used for lubrication. The drilling torques and thrust forces during micro-drilling experiments recorded by the torque/load cells. They reported that in addition to significantly increasing the number of drilled holes and reduction of drilling torques and thrust forces, nanofluid MQL enhances the quality of drilled holes due to its effectiveness in elimination of chips inside the drilled holes and burrs around it, resulting in enhanced productivity.

The effect of nanofluid-MQL related parameters (nozzle distance, volume concentration of nanofluid and air pressure) on the micro-drilling of 7075-T6 aluminium alloy with a micro-drill tool (DIXI 1135) of $200 \mu \mathrm{m}$ under different lubrication media of dry, MQL and nanofluid MQL were evaluated [32]. The variation of the lubrication parameters with thrust force and torque, temperature, tool wear and micro-drilling chips and burrs investigated. The experiments conducted under the following conditions: spindle speed- 48, $000 \mathrm{rpm}$, feed rate- $8 \mu \mathrm{m} / \mathrm{rev}$ and drilling depth- $0.52 \mathrm{~mm}$. They opined that the use of nanofluid MQL significantly reduces the micro-drilling force and torque in addition to reducing burr wear in the micro-drilling tool as shown in Fig. 3. Nanofluid inclusion in base fluid enhances the drilling process over the pure MQL and other lubrication as thrust forces and torques significantly reduced in addition to the efficient removal of chips from drilled holes thereby producing quality holes.

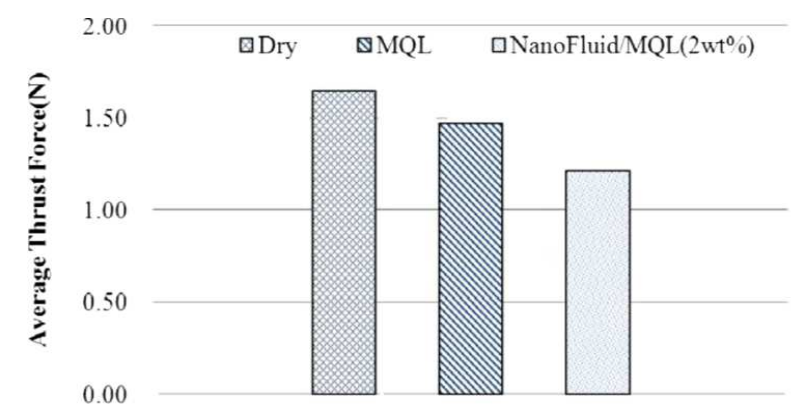

Fig. 3 Effect of thrust force under different lubricating condition of dry, pure MQL and nanofluid MQL [32]

3) Turning Operation with MQL Nanofluid: Several researchers reported the enhancement of MQL with nanofluid application. The effect of nanoparticles suspension in vegetable oil on surface roughness, tool wear, cutting forces and temperature dissipation during the turning operation of Inconel 600 of $20 \mathrm{~mm}$ diameter using coated carbide tool inserts (CNMG1 20 408-HF) was studied [33]. The experiments conducted under the following conditions: cutting speed $(40,50$ and $60 \mathrm{~m} / \mathrm{min})$, feed rate $(0.08,0.12$ and $0.16 \mathrm{~mm} / \mathrm{rev})$ and depth of cut $(0.4,0.8$ and $1.2 \mathrm{~mm})$.
$\mathrm{Al}_{2} \mathrm{O}_{3}$ nanoparticle and Coolube vegetable oil with flow rate of $100 \mathrm{ml} / \mathrm{h}$ used for lubrication incorporated with MQL technique and dry cutting. The nanolubricants prepared in two varying concentrations of $4 \%$ volume and $6 \%$ volume. The surface roughness measured by a Taylor-Hobson Surtronic 3+ Talysurf while the K-type standard thermocouple and the four-component piezo electric Kistler dynamometer were used to measure the temperature at the interface and the cutting forces respectively. They reported that addition of $\mathrm{Al}_{2} \mathrm{O}_{3}$ nanoparticles in MQL resulted in significant reduction of tool tip temperature, cutting forces and tool wear when compared with dry and pure MQL conditions in addition to better chip formation. The tool wear shown graphically in Fig. 4 and surface roughness improved significantly and further enhanced with increase of nanoparticle concentration.

The effect of nano graphite suspended in water soluble oil with MQL technique during turning of AISI 1040 steel using HSS and cemented carbide (CNMG $120408 \mathrm{H}-13 \mathrm{~A})$ tools was studied [34]. The effect on cutting force, temperature, surface roughness and tool flank wear evaluated using the nano cutting fluid lubricant. The experiments conducted under the following cutting condition: cutting speed of 105 $\mathrm{m} / \mathrm{min}$, feed rate of $0.14 \mathrm{~mm} / \mathrm{rev}$ and $1 \mathrm{~mm}$ depth of cut. Nano cutting fluid of nano graphite particles of $80 \mathrm{~nm}$ and water soluble oil with flow rates of 5,10 and $15 \mathrm{ml} / \mathrm{min}$ were used for lubrication. The temperature was measured the shielded K-type thermocouple embedded at the bottom of tool holder. The cutting force and the surface roughness measured by Kistler piezo electric dynamometer model 9272 and Talysurf of diamond stylus material respectively. It observed that under constant cutting conditions, enhanced reduction in flank wear, cutting temperature, cutting forces and improved surface roughness achieved with cutting fluids with nanoparticle when compared with pure cutting fluid.

The effect of nanographite dispersed in vegetable-based oil and ester oil as base fluid during turning of AISI 1045 steel with two cutting inserts of uncoated carbide investigated [35]. They reported that application of graphite oil-based nanofluid MQL significantly reduced the cutting force and temperature as shown in Fig. 5. In comparison with dry, the application of nanofluid reduced the temperature by $11.9 \%$ and $21 \%$ at cutting speeds of 55 and $96 \mathrm{~m} / \mathrm{min}$ respectively. The performance of vegetable oil based nanofluid with dispersion of molybdenum disulphide nanoparticle $\left(\mathrm{nMoS}_{2}\right)$ in different based oils of coconut (CC), canola (CAN) and sesame (SS) in turning AISI 1040 steel was evaluated [36]. Experiments were conducted under the following cutting conditions: cutting speed (40,60 and $100 \mathrm{~m} / \mathrm{min})$, feed rate $(0.14,0.17$ and $0.2 \mathrm{~mm} / \mathrm{rev})$ and constant depth of cut of $0.5 \mathrm{~mm}$. Machining conditions are selected in conformity with tool and work piece combination with MQL flow rate of $10 \mathrm{ml} / \mathrm{min}$. The nanofluids were prepared with nanoparticle inclusion of $0.25 \%, 0.5 \%, 0.75 \%$ and $1.0 \%$ in all the base oils. The cutting force were measured using Kistler 5070 dynamometer which is mounted onto the lathe tool post and the measured forces were tracked using dynoware software. Based on their observation, basic properties of nanofluids increased with increase nanoparticle inclusion in the base fluids. In addition, $\mathrm{CC}+0.5 \% \mathrm{nMoS}_{2}$ exhibited better performance over 
the other nanofluids and the cutting force, cutting temperatures, tool wear and surface roughness were reduced by $37 \%, 21 \%, 44 \%$ and $39 \%$ respectively when compared with dry machining.

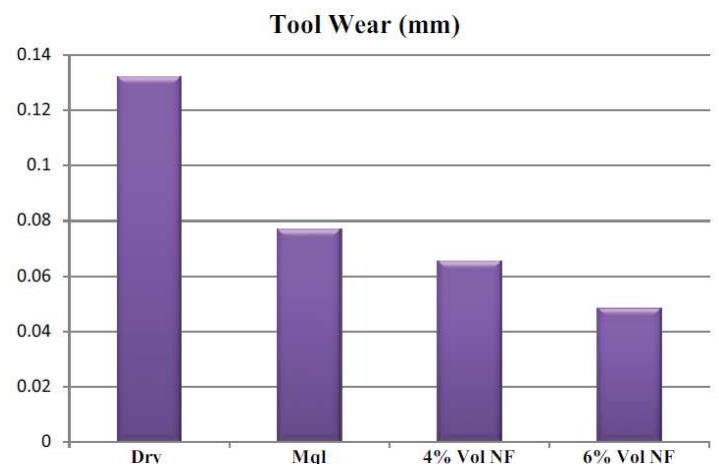

Fig. 4 Response graph at optimal parameters for tool wear [33]

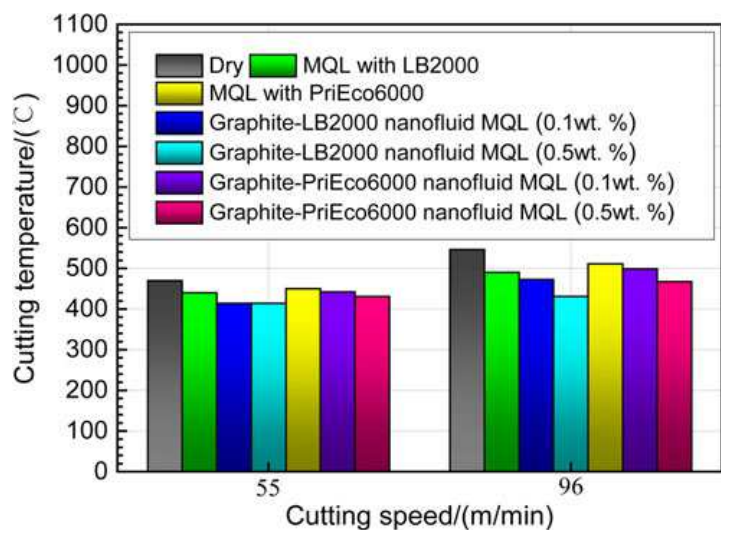

Fig. 5 Variation in cutting temperature with cutting speed for various cooling/lubrication conditions [35]

4) Milling Operation with MQL Nanofluid: Nanofluid integrated with MQL lubrication used to improve machining performance of milling operations. The effects of optimal MQL integrated with MWCNTs with dry cutting and pure MQL on the cutting force, cutting temperature, tool wear and surface roughness under same cutting conditions: cutting speed $(100,150$ and $200 \mathrm{~m} / \mathrm{min})$, feed rate $(0.05,0.1$ and 0.2 $\mathrm{mm} /$ tooth $)$, coolant angle of ejection $\left(90^{\circ}, 180^{\circ}\right.$ and $\left.270^{\circ}\right)$ and nanofluid concentration $(0,0.25$ and 0.5 wt. $\%$ ) were investigated [37]. The cutting force and cutting temperature were measured by a KISTLER dynamometer and a FLIR A320 infrared thermal imager respectively. The surface roughness meter (Mitutoyo, SJ-210) used to detect the surface quality. Tool wear value measured with SEM (JSM6380, JEOL) and a measuring microscope. They reported that MWCNTs-MQL provided efficient lubrication and the superior thermophysical properties of the nanofluid enhanced rapid elimination of excessive friction and heat from the tool and workpiece interface. The cutting temperature as indicated in Fig. 6, and tool wear are therefore reduced more effectively, which enhanced surface finish than dry cutting or pure MQL.

The effects of tribological properties of carbon onion nanotubes in mineral oil, on the cutting force reduction and surface quality improvement during CNC end-milling of Duralumin AL-2017-T4 under MQL lubrication was investigated by [38]. The machining test carried out on vertical machining centre (Sakai CNC MM-250 S3) with a maximum rotational speed of $5,000 \mathrm{~m} / \mathrm{min}$. The workpiece of dimension $50 \times 20 \times 10 \mathrm{~mm}^{3}$ was machined under the following cutting conditions: cutting speed, feed rates, and depths $(75.408 \mathrm{~m} / \mathrm{min}, 100 \mathrm{~mm} / \mathrm{min}$, and $1.0 \mathrm{~mm})$, respectively, based on the recommendations given by the tool manufacturer. Alumicut lubricant mineral based oil was chosen for lubrication because of its favourable lubrication characteristics to reduce friction at the tool-chip interface. They reported that carbon onion nanotubes could lower the cutting force and temperature at cutting zone thereby reducing wear rate and thus improving surface finish. It was observed that the MQL nanofluid lubrication gave better performance than the pure MQL and the reduction of cutting force and surface roughness improvement were further enhanced at higher carbon nanotubes concentration as shown in Fig. 7. The cutting force reduction and surface roughness improvement found to be $21.99 \%$ and $46.32 \%$ respectively when compared with the ordinary lubrication system at same cutting conditions. The results mainly attributed to the enhanced tribological properties of the carbon onion nanotubes, which act as billions of nanoscale quasispherical structure rolling elements at the tool-chip interface thereby reducing significantly coefficient of friction at the zone.

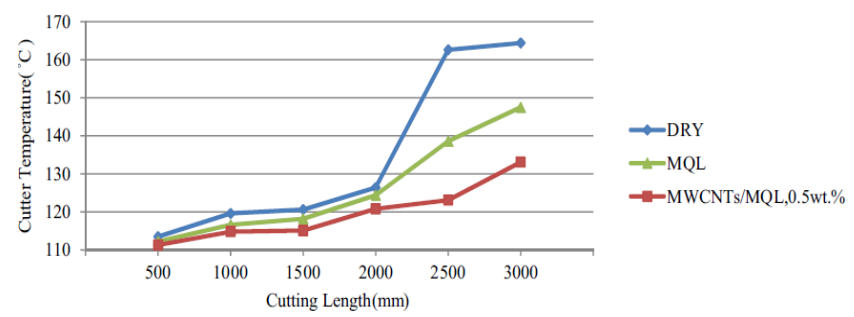

Fig. 6. Cutting temperature under different coolant conditions [37].

The effect of nanographene enhanced lubricant during ball milling of AISI 1045 steel with a $25 \mathrm{~mm}$ diameter ballnose TiAlN coated carbide inserts (ZPFG250-PCA 12M) under MQL nanofluid (0.1 and 1 wt. $\%)$ and pure vegetable oil MQL was investigated [39]. The ball milling experiments were conducted under the following cutting parameters: cutting speed range (3500 and $4500 \mathrm{rpm}$ ), constant feed rate of $2500 \mathrm{~mm} / \mathrm{min}$ and depth of cut (axial $-1 \mathrm{~mm}$ and radial $0.6)$ to evaluate the effect of the lubrication techniques on the flank and central wears. They reported that nanographene enhanced lubricant exhibited better performance than the pure MQL especially for the central wear.

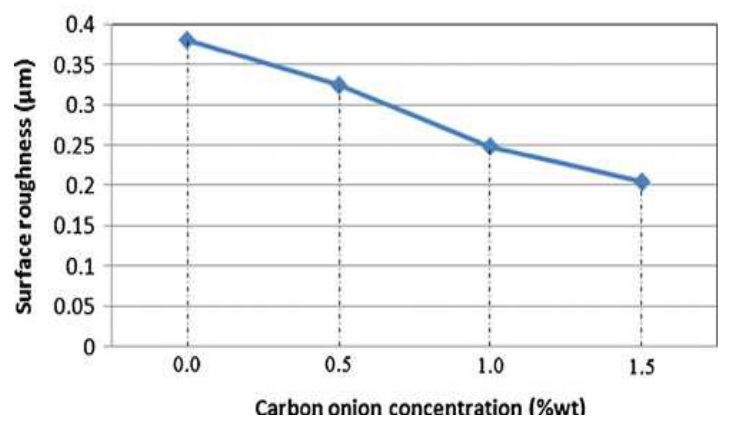

Fig. 7 Surface roughness recorded at different carbon onion concentration [38] 


\section{RESULT AND DISCUSSION}

Nanofluid integration with MQL has improved machining output over time in comparison with pure MQL or other lubrication methods. Machining parameters such as cutting force, cutting temperature, tool and flank wear, surface roughness etc. have improved greatly in addition to reduction of loads on the environment and enhanced safety of the personnel. The cutting force in grinding [27], [29][30], drilling [31], turning [33]-[36] and milling [37]-[38] decreased significantly with the use of nanofluid integrated with MQL technique when compared to pure MQL and other lubrication medium. From Fig. 2a, the comparison of nanofluid MQL with water and conventional coolant under MQL indicated superior performance of the nanofluid MQL lubrication. The force reduction could be attributed to the enhanced lubrication and cooling characteristics shown by nanofluids. Fig. $2 b$ shows the how increase of volume concentration of nanoparticles lowers the grinding force ratio $(\mathrm{G})$ which is important criteria for enhanced lubrication in grinding. The optimum value of the grinding force ratio was attained at $8 \%$ for CNTs-MoS $\mathrm{M}_{2}$ mixed and $\mathrm{MoS}_{2}$ while $\mathrm{CNTs}$ at $6 \%$. Increase of concentration beyond these optimum nanoparticle concentrations may result in agglomeration thereby increasing G-value that may impede efficient lubrication.

Surface roughness of machined component always enhanced with nanofluid MQL than other lubrication method as efficient lubrication reduces cutting force, friction between workpiece-tool interface and conduction of heat away from the cutting zone [37]. The surface roughness of machined component is further enhancing with increase of nanoparticles concentration in base cutting fluid as shown in Fig. 7. Similarly, increase of nanoparticle concentration in vegetable oil from $0.1 \mathrm{wt} \%$ to $0.5 \mathrm{wt} \%$ in comparison with ester oil at same level of increment indicated a superior performance of the vegetable oil based nanofluid over the ester oil based nanofluid as can be seen in Fig. 5. The temperature generated in machining reduced with the elimination of excessive friction and heat away from workpiece and tool interface. The superior performance of nanofluid MQL over pure MQL indicated in Fig. 6 in terms of temperature reduction. The tool wear has great impact on the surface finish of the machined component and the tool life of the cutting tool. The use of nanofluid integrated with MQL in machining reduces the cutting forces, temperature that influences reduction of excessive tool wear and elongation of tool life. Fig. 4 indicated a reduction of tool wear in MQL nanofluid in comparison with pure MQL and dry cutting. The tool life was enhanced by $45 \%$ with MQL $6 \% \mathrm{Al}_{2} \mathrm{O}_{3}$ in MQL as coolant when compared to dry cutting.

\section{CONCLUSIONS}

Cooling and lubrication are very important in metal cutting process due to the reduction of negative effect resulting from interaction of cutting tool and workpiece. Machinability factors such as tool wear, surface roughness, cutting force and chip morphology [40] are usually affected without efficient cooling strategy. Researchers have reported the introduction of nanoparticles in base cutting fluid into MQL lubrication technique and its improvement of lubrication and cooling. The efficiency of nanofluid in metal cutting operation can be attributed to the enhanced thermal conductivity and heat transfer coefficient that are key to its superior performance over other lubricants/cooling method. The effect of increase of volume concentration as it affects the thermal conductivity of nanofluid and its subsequent performance in application were evaluate. At higher volume concentration of nanoparticles, machining responses are further improved upon. However, it is observed that beyond certain level of increment of concentration, the effect is less significant while in some cases, it causes agglomeration of particles in base fluid that hinder efficient performance. The performance of nanofluid integrated with MQL in metal cutting in the areas of reduction of cutting force, cutting temperature, grinding force ratio $(\mathrm{G})$ in grinding, surface roughness improvement, tool wear reduction thereby elongating tool life and the safety of environment and personnel are highlighted.

\section{ACKNOWLEDGMENT}

The authors wish to thank Universiti Teknologi Malaysia and Sriwijaya University for the cooperation and assistance throughout conducting this research. Special appreciation to the Ministry of Higher Education (MOHE) Malaysia and Research Management Centre of UTM for the financial support.

\section{REFERENCES}

[1] J. P. Byers, Metal Working Fluids, 1st edition, USA: CRC, 1994.

[2] Y. Wei and X. Huaqing, "A review on nanofluids: preparation, stability mechanisms and applications", Journal of Nanomaterials, vol. 2012, pp. 1-17, 2012.

[3] K. Weinert, I. Inasaki, J. W. Sutherland and T. Wakabayashi, "Dry machining and minimum quantity lubrication", CIRP Annals Manufacturing Technology, vol. 53, pp. 511-537, 2004.

[4] T. Tawakoli, M. J. Hadad, M. H. Sadeghi, A. Daneshi, S. Stöckert and A. Rasifard, "An experimental investigation of the effects of workpiece and grinding parameters on minimum quantity lubrication-MQL grinding", International Journal of Machine Tools and Manufacture, vol. 49, pp. 924-932, 2009.

[5] H. Safari, S. Sharif, S. Izman, H. Jafari, and D. Kurniawan, "Cutting force and surface roughness characterization in cryogenic high speed end milling of Ti6Al4V ELI", Materials and Manufacturing Processes, vol.29, Issue 3, pp. 350-356, 2014.

[6] S. Sharif, M. A. Hisyam, D. Kurniawan and E. A. Orady, "Performance evaluation of vegetable oil as an alternative cutting lubricant when end milling stainless steel using TiAlN coated carbide tool", Transaction of the North American Manufacturing Research Institution of SME, vol. 37, pp. 9-13, 2009.

[7] M. Rahman, A. Senthil Kumar and M. U. Salam, "Experimental evaluation on the effect of minimal quantities of lubricant in milling", International Journal of Machine Tools \& Manufacture, vol. 42, pp. 539-547, 2002.

[8] I. Manna, "Synthesis, characterization and application of nanofluid An overview", Journal of the Indian Institute of Science, vol 89:1, pp. 21-33, 2012.

[9] S.U.S. Choi, "Enhancing thermal conductivity of fluids with nanoparticles: Developments and applications of Non-Newtonian flows", ASME' 95, paper CONF-951135-29, pp.1-8, 1995

[10] H. Masuda, A. Ebata, K. Teramae and K. Hishiunma, "Alternation of thermal conductivity and viscosity of liquid by dispersing ultrafine particles (dispersion of $\mathrm{Al} 2 \mathrm{O} 3, \mathrm{SiO} 2$ and $\mathrm{TiO} 2$ ultrafine particles)", Netsu Busei, Japan, pp. 227-233, 1993

[11] S. Krishnamurthy, P. Bhattacharya, P. E. Phelan and R. S. Prasher, "Enhanced mass transport in nanofluids", Nano Letter 6, vol. 3, pp. $419-423,2006$.

[12] D. T. Wasan, and A. D. Nikolov, "Spreading of nanofluids on solids", Nature 423, pp. 156-159, 2003. 
[13] Y. S. Touloukian, R. W. Powell, C. Y. Ho, and P. G. Klemens, "Thermo-Physical Properties of Matter", New York, USA, Plenum Press, vol. 2, 1970

[14] S. Lee, S.U.S. Choi, S. Li, and J. A. Eastman, "Measuring thermal conductivity of fluids containing oxide nanoparticles", ASME Journal of Heat Transfer vol. 121, Issue 2, pp. 280-289, 1999.

[15] J. A. Eastman, S.U.S. Choi, S. Li, W. Yu and L. J Thompson, "Anomalously increased effective thermal conductivities of ethylene glycol based nanofluids containing copper nanoparticles", Applied Physics Letter, 78 (6), 718 - 720, 2001.

[16] T. Tun-Ping and Y. Chao-Chieh, "Heat dissipation performance of MWCNTs nano-coolant for vehicle", Experimental Thermal and Fluid Science, 49, pp. 22-30, 2013.

[17] Y. Hwang, H. S. Park, J. K. Lee and W. H. Jung, "Thermal conductivity and lubrication characteristics of nanofluids". Current Applied Physics, vol. 61 pp. 67-71, 2006.

[18] X. Wang and A. S. Mujumdar, "A review on nanofluids - Part II: Experiments and Applications", Brazilian Journal of Chemical Engineering vol. 25, No. 04, pp. 631-648, 2008.

[19] W. Daungthongsuk and S. Wongwises, "A critical review of convective heat transfer of nanofluids", Renewable and Sustainable Energy Reviews II, pp. 797-817, 2007.

[20] J. Albadr, S. Tayal and M. Alasadi, "Heat transfer through heat exchanger using $\mathrm{Al} 2 \mathrm{O} 3$ nanofluid at different concentrations, Case Studies in Thermal Engineering", vol. 1, Issue 1, pp. 38-44, 2013.

[21] I. M. Mahbubul, R. Saidur, and M.A. Amalina, "Latest developments on the viscosity of nanofluids", International Journal of Heat and Mass Transfer, vol. 55, pp. 874-885, 2012.

[22] S.U.S. Choi D. A. Singer and H. P. Wang, "Development and Application of Non-Newtonian Flows", Vol. FED 231. New York: ASME; 99-105, 1995

[23] R. Saidur, K. Y. Leong and H. A. Mohammad, "A review on applications and challenges of nanofluids" Renewable and Sustainable Energy Reviews, vol. 15 pp. 1646-1668, 2011.

[24] Y. Shokoohi and E. Shekarian, "Application of nanofluids in machining processes - A review", Journal of Nanoscience and Technology, vol. 2 (1), pp. 59 - 63, 2016.

[25] M. Sayuti, O. M. Erh, A. D. Ahmed Sarhana and M. Hamdi, "Investigation on the morphology of the machined surface in end milling of aerospace AL6061-T6 for novel uses of $\mathrm{SiO} 2$ nanolubrication system", Journal of Cleaner Production, vol. 66, pp. 655-663, 2014.

[26] Y. Su, G. Le and C. Dandan, "An investigation on tribological properties and lubrication mechanism of graphite nanoparticles as vegetable based oil additive", Journal of Nanomaterials, Vol. 16, pp. $1-7,2015$.

[27] D. Setti, S. Ghosh, and P. Venkateswara Rao, "Application of nano cutting fluid under minimum quantity lubrication (MQL) technique to improve grinding of Ti-6Al-4V alloy", World Academy of Science, Engineering and Technology, vol. 6, pp. 10-24, 2012.

[28] Y. Zhang, C. Li, D. Jia, B. Li, Y. Wang, M. Yang, Y. Hou and X. Zhang, "Experimental study on the effect of nanoparticle concentration on the lubricating property of nanofluids for MQL grinding of Ni-based alloy", Journal of Materials Processing Technology, vol. 232, pp. $100-115,2016$.

[29] B. Shen, A. J. Shih and S. C. Tung, "Application of nanofluids in minimum quantity lubrication grinding", Tribology Transactions, vol. 51, No. 6, pp. 730-737, 2008.

[30] P. Lee, J. S. Nam, C. Li and S. W. Lee, "An experimental study on micro grinding process with nanofluid minimum quantity lubrication (MQL)", International Journal of Precision Engineering and Manufacturing, vol. 13, No. 3, pp. 331-338, 2012.

[31] J. S. Nam, P. H. Lee and S. W. Lee, "Experimental characterization of micro-drilling process using Nanofluid minimum quantity Lubrication", International Journal of Machine Tools \& Manufacture, vol. 51, pp. 649-652, 2011.

[32] W. T. Huang, D. H. Wu and J. T. Chen, "Robust design of using nanofluid/MQL in micro-drilling", International Journal of Advanced Manufacturing Technology, pp. 1-7, 2015a.

[33] V. Vasu and G. Pradeep Kumar Reddy, "Effect of minimum quantity lubrication with $\mathrm{Al} 2 \mathrm{O} 3$ nanoparticles on surface roughness, tool wear and temperature dissipation in machining Inconel 600 alloy", Proc. IMechE, 2011 Vol. 225 Part N: Journal of Nanoengineering and Nanosystems. 2011

[34] M. M. S. Prasad and R. R. Srikant, "Performance evaluation of nanographite inclusions in cutting fluids with MQL technique in turning of AISI 1040 steel", International Journal of Research in Engineering and Technology, vol. 02, Issue 11, pp. 381-393, 2013.

[35] Y. Su, L. Gong, B. Li, Z. Liu and D. Chen, "Performance evaluation of nanofluid MQL with vegetable-based oil and ester oil as base fluids in turning", International Journal of Advanced Manufacturing Technology, vol 83, pp. 2083-2089, 2016.

[36] R. Padmini, P. Vamsi Krishna and G. Krishna Mohana Rao "Effectiveness of vegetable oil based nanofluids as potential cutting fluids in turning AISI 1040 steel", Tribology International, vol. 94, pp. 490-501, 2016.

[37] W. T. Huang, D. Wu, S. Lin and W. Liu, "A combined minimum quantity lubrication and MWCNT cutting fluid approach for SKD 11 end milling", International Journal of Advanced Manufacturing Technology, pp. 1-8, 2015.

[38] M. Sayuti, A. D. Ahmed Sarhan, T. Tanaka, M. Hamdi and Y. Saito, "Cutting force reduction and surface quality improvement in machining of aerospace duralumin AL-2017-T4 using carbon onion nanolubrication system", International Journal of Advanced Manufacturing Technology, vol. 65, pp. 1493 - 1500, 2013.

[39] P. Kyung-Hee, B. Ewald \& P. Y. Kwon, "Effect of nano-enhanced lubricant in minimum quantity lubrication ball milling", Journal of Tribology, Transactions of the ASME, vol. 133, pp. 031803:1-8, 2011.

[40] A. U. Patwari, M. N. Mahmood, and M. D. Arif. "Improvement of machinability of mild steel during turning operation by magnetic cutting". International Journal on Advanced Science, Engineering and Information Technology, 2 (3), 207-210, 2012. 